\title{
Exploring Indirect Inguinal Hernia Recurrence Technical Cause Following Laparoscopic Trans-Abdominal Pre- Peritoneal Hernioplasty
}

\author{
Mohamed Mahmood Nasr, MB, BCh, MSC, FRCS, MD*D \\ Head of Endoscopic Surgery Unit, Consultant Endoscopic \& General Surgery, King Fahad Hospital, Riyadh $\mathrm{MOH}$, \\ Kingdom of Saudi Arabia
}

\begin{abstract}
Purpose: Review of literature has revealed no definite cause behind indirect inguinal hernia recurrence following laparoscopic trans-abdominal pre-peritoneal hernioplasty. As a matter of surgeons' preference such cases are preferred to be managed through a different approach; either trans-inguinal pre-peritoneal or even open procedure to reduce the needed dissection effort. The author preferred to re-operate through the same previous laparoscopic trans-abdominal pre-peritoneal hernioplasty approach searching for the potential cause behind hernia recurrence.
\end{abstract}

Methods: Thirty one patients having recurrent reducible indirect inguinal hernia within the first six months from the original procedure which were collected from other centres than that of the author's. Laparoscopic procedure has been defined to approach the hernia sac leading point without distortion.

Results: The study has revealed a unique finding through all cases with different intensities; that is presence of remnant of dense adhesion between the neck of the hernia sac and the medial side of the spermatic cord. Such adhesion is marking incomplete separation of the hernia sac. Patients' epidemiology, operative and follow up are all tabulated. The author did not fix the mesh nor excise the hernia sac to verify such issues as reasons for hernia recurrence. Follow up showed no recurrence in any of the cases.

Conclusions: The study has discovered a highly potential reason for hernia recurrence. Incomplete dissection of the hernia sac from the medial aspect of the spermatic was a unique finding through all cases. No fixation of mesh or retaining the hernia sac proved no reason for recurrence through the follow up duration.

\section{Keywords}

Laparoscopic trans abdominal pre-peritoneal hernioplasty, Trans inguinal pre-peritoneal hernioplasty, Hernia recurrence, Neck of hernia sac leading point

\section{Abbreviations}

TAPP: Laparoscopic Trans Abdominal Pre Peritoneal Hernioplasty; TIPP: Trans Inguinal Pre-Peritoneal Hernioplasty

\section{Introduction \& Review of Research Concept}

In spite that laparoscopic hernioplasty is still not the gold standard for repair, recent worldwide figures state that 15$20 \%$ of hernias are being done laparoscopically. Laparoscopic hernioplasties reduced the recurrence rates to less than $0.5 \%$ in most series. Technically the main two issues for the hernioplasty technique are dissection and separation of the hernia sac from the contents of the spermatic cord and positioning a mesh over the myo-pectineal ring. So, theoretically the reason of recurrence should be related to either one or both of these two issues. It has been well
*Corresponding author: Mohamed Mahmood Nasr, Head of Endoscopic Surgery Unit, Consultant Endoscopic \& General Surgery, King Fahad Hospital, Riyadh $\mathrm{MOH}$, Kingdom of Saudi Arabia, Tel: +966-543-606-109

Accepted: November 30, 2021

Published online: December 02, 2021

Citation: Nasr MM (2021) Exploring Indirect Inguinal Hernia Recurrence Technical Cause Following Laparoscopic TransAbdominal Pre-Peritoneal Hernioplasty. Adv Laparoscopy 4(1):123-126 
Citation: Nasr MM (2021) Exploring Indirect Inguinal Hernia Recurrence Technical Cause Following Laparoscopic Trans-Abdominal PrePeritoneal Hernioplasty. Adv Laparoscopy 4(1):123-126

documented that laparoscopy is more sensitive than clinical examination and inspection during open surgical procedure in documenting hernias. In addition, review of literature has revealed no definite proofs regarding the cause behind indirect inguinal hernia recurrence following laparoscopic trans-abdominal pre-peritoneal hernioplasty (TAPP) [1-3].

As a matter of surgeons' preference such cases are preferred to be managed through a different approach; either trans-inguinal pre-peritoneal (TIPP) or even open procedure. In literature, a single paper has been documenting the value of TAPP in exploration of recurrent inguinal hernia [4]. The author tried recurrence repair through the same previous TAPP approach searching for the potential cause behind hernia recurrence. Dependently, in this study we rely on exploring the reason for hernia recurrence on TAPP.

\section{Materials \& Methods}

This is a case series pilot study that has recruited cases with recurrent indirect inguinal hernia following TAPP procedure. Between January 2014 and December 2017, 31 patients having recurrent inguinal hernia following laparoscopic TAPP procedures were referred from different hospitals to author's centre. Recurrence accepted only within the first six months from the original surgery to differentiate between the acute and the chronic pathology. Patients were diagnosed pre-operatively regarding hernia type degree of descent and reducibility through clinical examination and groin ultrasonography. The method of operative verification is exploration during TAPP procedure. The minimum follow up duration for study cases is fourteen months.

\section{Surgical Technique and exploration for cause of recurrence}

1. Patient is generally anesthetized, positioned, draped and skin is prepared as usual.

2. Single dose third generation cephalosporin antibiotic is given as procedure start.

3. Peritoneal gas insufflation and three trocars are inserted at supra-umbilical and both loins as usual.

4. Identification of the hernia sac and tension traction of the fundus intra-peritoneally will explore hernia sac neck adhesion to the spermatic cord at the level of the internal ring. The neck of the hernia sac area showing maximum fibrosis (chronic long standing fibrosis) is claimed as the leading point for the sac extrusion out of the peritoneal cavity. This point is claimed to be left un-dissected during the original procedure and has led to hernia recurrence.

5. The peritoneum is then incised transversely 4 to $5 \mathrm{~cm}$ beyond the level of neck of the hernia sac and wide pocketing for the mesh is made. Visualization of the point of maximum fibrosis and adhesions extra-peritoneally prior to dissection. Such point is the chronological oldest point to stay in the extra-peritoneal space and is considered the sac leading point to recurrence. This point is proposed to be missed out of dissection during the previous hernioplasty procedure (Figure 1).
6. Hernia mesh Mersilene (6 $\mathrm{cm}$ wide and $9 \mathrm{~cm}$ long) is introduced in to the extra-peritoneal space as a transverse roll and positioned vertically in the medial extreme on the pubic tubercle. The mesh sheet is spread to overly the myopectineal rig. Mesh fixation is left to surgeon's preference. No fixation is ever made as fixation to verify as a cause of hernia recurrence (Figure 2).

7. Peritoneum is closed with Endo-suture Silk 2/0. Starting with Pearce string suture around the neck of the hernia sac and closure of the string followed by closure of the peritoneal window in continuous suturing. Upon reaching the lateral end of the peritoneal incision the fundus of the hernia sac is taken in the stitch line and transfixed by a final knot. The hernia sac is retained to verify as a cause for hernia recurrence (Figure 3).

8. Abdominal cavity is deflated of gas, ports removed, skin incisions are infiltrated with lidocaine $2 \%$ and closed with sub-cuticlar suture using 4/0 Vic-Rapid.

9. Scrotum and groin are compressed to evacuate surgical emphysema introduced.

\section{Postoperative care}

All patients were treated as day care cases. Once patient gains full consciousness intravenous fluids are discontinued and oral fluids are started. Within two hours the patient is allowed to have a light meal. Patient is instructed assisted ambulation at first and later on his own. Patients were discharged on the same night of the procedure.

\section{Follow-up schedule}

First follow up visit is planned within 4-6 days from discharge date. Monthly follow up phone call was maintained for at least 14 months. Instructions given to patients for clinic visit if any complication symptom is experienced.

\section{Results}

The study has explored the surgical field through the same approach of the previous procedure to preserve the pathology and tissue relations. Exploration of the recurrent hernia has showed a unique observation giving the reason for hernia recurrence; that is neglecting circumferential dissection for the sac neck at the level of the internal ring. Retaining adherent neck of sac to the medial side of the spermatic cord;

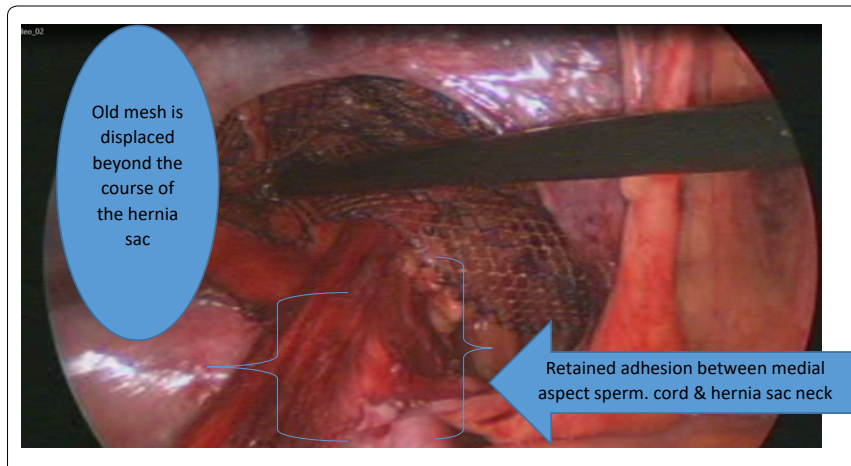

Figure 1: Exploring hernia recurrence cause. 


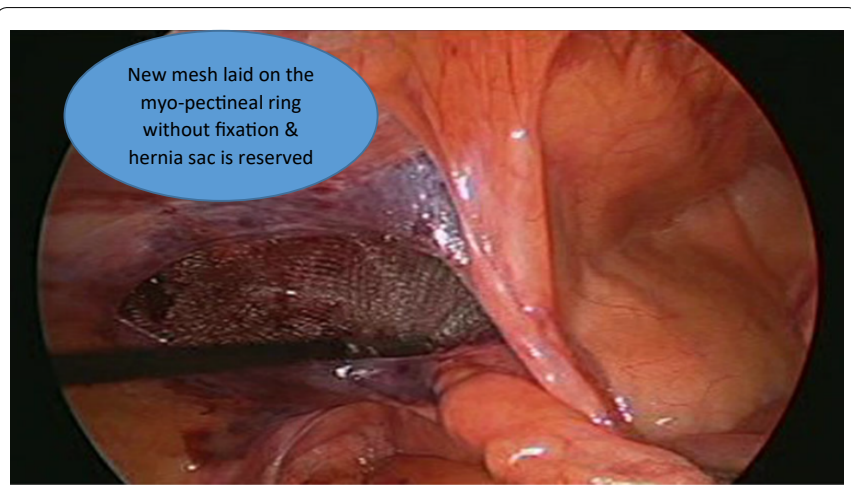

Figure 2: Complete dissection of hernia sac from the spermatic cord and new mesh placement without fixation.

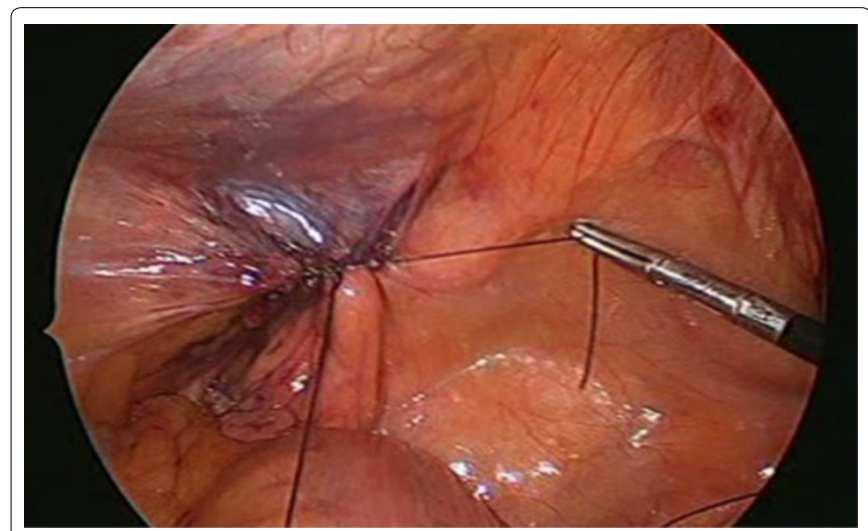

Figure 3: Closure of peritoneal window with sac transfixation

would leave a leading point to guide a new sac through the supra-inguinal division of myo-pectineal orifice generating a recurrent hernia. Displacement of the mesh by the protruding sac has occurred even with a fixed mesh to the abdominal wall. There was no post-operative complication namely; persistent groin pain and numbness, testicular pain, injury to the vas deferens, seroma or hematoma formation, vascular injury, mesh infection or migration. Follow up of cases has proved no hernia recurrence over a median duration of 36 months. In addition the study has proved that not excising the hernia sac or not fixing the mesh are definitely not potential recurrence factors.

Results are tabulated as follows:

- Epidemiology data are summarized in (Table 1)

- Operative data are summarized in (Table 2)

- Follow up data are summarized in (Table 3)

\section{Discussion}

Literature has incriminated several potential causes of indirect inguinal hernia recurrence without evidence namely; leaving extra-peritoneal lipoma un-excised [5], not excising the hernia sac [6], surgeon's inexperience, inadequate dissection, improper mesh size, in-appropriate mesh fixation, missed hernia sac, migration of prosthesis, and insufficient prosthesis overlap of hernia defect [7]. All these claimed causes except for the sac dissection has proved of no relevance. Not excising the hernia sac or fixing the mesh are proved of no relation to indirect inguinal hernia recurrence [8]. The current study has tried to explore the cause of indirect inguinal hernia recurrence and management of recurrent hernia verifying not fixing the mesh and not excising the hernia sac. The author has applied the same concept in a previously published bigger sample with claimed optimal results [8]. Verification of the technique of circumferential dissection of the hernia sac neck at the level of the internal ring is requested to apply on large number sample studies. Critic is invited.

Table 1: Patients' clinical presentation data.

\begin{tabular}{|l|c|c|}
\hline Item & $\begin{array}{c}\text { Value / } \\
\text { Range }\end{array}$ & Mean \\
\hline Total number of patients & 31 & \\
\hline Age (Years) & $29-51$ & $38 \pm 3.1$ \\
\hline Gender & $31: 0$ \\
\hline Male : Female Ratio & \\
\hline Patients habits / Related drug intake & \\
to disease & \\
\hline $\begin{array}{l}\text { Smokers } \\
\text { Chronic obstructive airway disease }\end{array}$ & 9 \\
\hline $\begin{array}{l}\text { Chronic constipation } \\
\text { Benign prostatic hyperplasia }\end{array}$ & 3 \\
(Symptomatic) & 6 \\
\hline
\end{tabular}

Table 2: Patients' operative data.

\begin{tabular}{|c|c|c|}
\hline Item & Value/Range & Mean \\
\hline $\begin{array}{l}\text { American Society of Anesthesia } \\
\text { Classification } \\
\text { ASA Class } \\
\text { Class I } \\
\text { Class II }\end{array}$ & $\begin{array}{c}23 \\
8\end{array}$ & \\
\hline $\begin{array}{l}\text { Type of recurrent inguinal hernias } \\
\text { as diagnosed intra-operatively } \\
\text { Indirect Inguinal Hernia } \\
\text { Size of indirect inguinal hernia } \\
\text { Inguinal : Inguino-scrotal }\end{array}$ & $\begin{array}{l}\text { All Patients } \\
\qquad 31 \\
13: 18\end{array}$ & \\
\hline $\begin{array}{l}\text { Appearance of peritoneal window } \\
\text { just prior to mesh introduction } \\
\text { ( } \mathbf{N}=\mathbf{3 1} \text { ) } \\
\text { Completely bloodless field } \\
\text { Hemorrhagic spots field } \\
\text { Contused field } \\
\text { Diffuse hematoma in the field } \\
\text { Blood oozing in the field }\end{array}$ & $\begin{array}{l}25 \\
5 \\
1 \\
0 \\
0\end{array}$ & \\
\hline $\begin{array}{l}\text { Tranfixation of hernial sac within } \\
\text { line of peritoneal closure } \\
\text { (No hernia sac excision) }\end{array}$ & $\begin{array}{l}\text { All Patients } \\
31\end{array}$ & \\
\hline $\begin{array}{l}\text { Procedure time (minutes) } \\
\text { (from first port insertion till last port } \\
\text { removal) }\end{array}$ & $60-35$ & $41 \pm 2$ \\
\hline $\begin{array}{l}\text { Number of no mesh fixation cases } \\
(N=31)\end{array}$ & $\begin{array}{l}\text { All patients } \\
31\end{array}$ & \\
\hline $\begin{array}{l}\text { Recognized intra operative } \\
\text { complications } \\
\text { - Injury to the vas deferens } \\
\text { - Vascular injury } \\
\text { - Intra-abdominal visceral injury }\end{array}$ & $\begin{array}{c}\text { Nil } \\
0 \\
0 \\
0\end{array}$ & \\
\hline $\begin{array}{l}\text { Number of cases laparoscopic } \\
\text { procedure converted to open } \\
\text { procedure }\end{array}$ & Nil & \\
\hline
\end{tabular}


Table 3: Patients' post-operative data.

\begin{tabular}{|l|c|c|}
\hline Item & $\begin{array}{c}\text { Value/ } \\
\text { Range }\end{array}$ & Mean \\
\hline $\begin{array}{l}\text { Postoperative fasting duration after being } \\
\text { fully conscious (hours) }\end{array}$ & $2-4$ & $3.9 \pm 0.1$ \\
\hline $\begin{array}{l}\text { Potential postoperative complications } \\
\text { - Scrotal emphysema for more than 6 hours }\end{array}$ & $\begin{array}{c}\mathrm{Nil} \\
\text { - Groin pain and numbness } \\
\text { - Testicular pain }\end{array}$ & 0 \\
\hline - Hematoma or seroma formation & 0 & \\
\hline - Mesh infection or migration. & 0 & \\
\hline $\begin{array}{l}\text { Postoperative Pain Scoring by patients } \\
\text { *(on scale of 0-5) }\end{array}$ & $1-3$ & $1 \pm 0.7$ \\
\hline Hospitalization time (hours) & $9-13$ & $10.2 \pm 1$ \\
\hline Re-hospitalized cases after discharge & $\mathrm{Nil}$ & \\
\hline Duration follow up (months) & $14-61$ & $36 \pm 5.3$ \\
\hline $\begin{array}{l}\text { Number of cases showed hernia } \\
\text { recurrence }\end{array}$ & $\mathrm{Nil}$ \\
\hline $\begin{array}{l}\text { Patients needed any surgical procedure } \\
\text { during follow up duration }\end{array}$ & $\mathrm{Nil}$ \\
\hline
\end{tabular}

${ }^{*}$ (Pain Score System: $\mathbf{1}=$ minimal pain need no analgesia; $\mathbf{2}=$ pain needs oral analgesia once; $\mathbf{3}=$ pain needs regular oral analgesia; $\mathbf{4}=$ pain needs parenteral analgesia; $\mathbf{5}=$ intolerable pain needs sedation)

\section{Compliance with Ethical Standards}

\section{Conflict of interest}

The author declares no conflict of interest related to the study. The submitted research has received no supporting funds.

\section{Ethical approval}

The study required no institutional review approval.

\section{Human and animal rights}

The research does not include any studies on human participants or animals.

Informed consent an informed consent has been given by each of the study patients declaring acceptance to be anonymously involved in the study that involves no un-usual nor experimental management for his /her disease.

\section{Statement of disclosure}

This research complies with research ethical and scientific rules and regulations stated by the Ministry of Health, Kingdom of Saudi Arabia.

\section{Statement of Author Contribution}

The submitted paper is "a single author research" taking all responsibility for every portion of the content; namely:

1. Conception and design of the work, analysis, interpretation of data for the work; AND

2. Drafting the work and revising it critically for important intellectual content; AND

3. Final approval of the version to be published; AND

4. Agreement to be accountable for all aspects of the work in ensuring that questions related to the accuracy or integrity of any part of the work are appropriately investigated and resolved.

\section{References}

1. Bracelet U, Mellilo P, Pignata G, et al. (2012) Which is the best laparoscopic approach for inguinal approach for inguinal hernia repair: TEP or TAPP? A systemic review of the literature with a network metaanalysis. Surg Endosc 26: 3355-3366.

2. Bittner R, Arregui M, Bisgaard T, et al. (2015) Update of guidelines on laparoscopic (TAPP) and endoscopic (TEP) treatment of inguinal hernia [Internal Endo Hernia Society] IEHS. Surg Endosc 2: 289-321.

3. O'Rourke A, Zell JA, Varkey Zell TT, et al. (2002) Laparoscopic diagnosis and repair of asymptomatic bilateral inguinal hernias. Am J Surg 183: 15-19.

4. Kockerling F, Schug Pass C (2017) Diagnostic laparoscopy as decision tool for re-recurrent inguinal hernia treatment following open anterior and laparo-endoscopic posterior repair. Front Surg 7: 4: 22.

5. Lau H (2007) Recurrence following extraperitoneal inguinal hernioplasty. Hernia 11: 415-418.

6. Stylianidis G, Haapamaki MM, Sund M, et al. (2010) Management of the hernial sac in inguinal hernia repair. Br J Surg 97: 415-419.

7. Neumayer L, Giobbie Hurder A, Jonasson O, et al. (2004) Open mesh versus laparoscopic mesh repair of inguinal hernia. $\mathrm{N}$ Engl J Med 350: 1819-1827.

8. Nasr M (2016) Early results of dual approach hernioplasty (DAH): An innovative laparoscopic inguinal hernioplasty technique. Surg Endosc 30: 1113-1118.

DOI: $10.36959 / 367 / 453$ 